\title{
NOVA VOZ NA MÚSICA BRASILEIRA
}

\section{ROMULO FRÓES}

\section{RESUMO}

Em meio à discussão sobre novos formatos e à profunda transformação nos meios de produção e difusão musical, este artigo busca identificar sinais de renovação na música popular brasileira. Favorecido pela transformação, o volume da produção musical atual é inédito. Se por um lado isso dificulta a identificação da boa música, por outro cria condições para a renovação. Esse contexto é analisado por meio do trabalho de cinco novas cantoras: Teresa Cristina, Roberta Sá, Céu, Mariana Aydar e Thalma de Freitas.

PALAVRAS-CHAVE: música popular brasileira; cantoras; samba.

\section{SUMMARY}

Against the background of the discussion concerning new formats and the profound transformation in the means of production and circulation of music, this article tries to identify signals of renovation within Brazilian popular music. Enhanced by this transformation, the amount of contemporary musical production is bigger than ever. If, on one hand, it makes good music more difficult to be identified, on the other it makes renovation possible. This context is analyzed through the work of five new singers: Teresa Cristina, Roberta Sá, Céu, Mariana Aydar e Thalma de Freitas.

KEYWORDS: Brazilian popular music; singers; samba.

Vivemos um momento de transição no modo como consumimos música. O formato físico parece estar com os dias contados e o futuro se desenha não mais nas redes de rádio e televisão, mas na rede mundial de computadores, em uma relação inédita entre criador e consumidor: é permitido a qualquer um produzir, divulgar e compartilhar suas criações, com quem quer que seja, em qualquer lugar do mundo. O volume do que é produzido hoje é incalculável e pode estimular novas discussões a respeito da canção popular. Contrariando a conquista dos tropicalistas, nos últimos anos as grandes gravadoras segmentaram o mercado e privilegiaram, a cada instante, um único estilo, balizados pelas vendas de discos. Assim, tiveram sua chance, cada qual na sua vez, o sertanejo, o axé e o pagode. Nesse novo sistema de compartilhamento de música, a segmentação não acabou, ao contrário, expandiu-se ao infinito. Como acontece com a pornografia, em que cada tara de cada habitante deste planeta aparece contemplada na internet, a música cria um sem- número de nominações - se um pesquisador tivesse a infeliz idéia de fazer uma nova enciclopédia de estilos musicais, atualizaria o mito de Sísifo. 
Se essa demanda de proporções estratosféricas parece dar impulso à formação de novos olhares sobre a música, a tarefa de identificá-los ganha a mesma proporção. Por achar que as cantoras continuam a desempenhar papel fundamental na discussão e difusão de novos caminhos na canção popular, escolhi cinco novas vozes para tentar encontrar indícios de alguma renovação na nova música popular brasileira. São elas: Teresa Cristina, Roberta Sá, Céu, Mariana Aydar e Thalma de Freitas.

A cantora Maria Rita declarou recentemente em entrevista coletiva sobre Samba meu, disco dedicado ao samba, que achou melhor não convidar Paulinho da Viola. Para ela, alguém de fora do samba gravar com alguém de dentro poderia soar como mera busca por autenticidade. Preferiu gravar Arlindo Cruz, ex-integrante do grupo Fundo de Quintal, autor de seis das catorze faixas do disco. Disse, ainda, ter músicas para pelo menos mais um disco, mas que preferiu não fazer um álbum duplo por achar uma coisa "meio arrogante".

No pólo oposto de Maria Rita, Teresa Cristina iniciou sua discografia em 2002, com dois discos inteiramente dedicados à obra de Paulinho da Viola, Teresa Cristina e Grupo Semente: a música de Paulinho da Viola. A primeira faixa do primeiro disco é "Meu mundo é hoje", clássico de Wilson Batista, imortalizado na voz do próprio Paulinho. "Meu mundo é hoje" é grafada no disco com o subtítulo "Eu sou assim", apelido pelo qual é mais conhecida, tirado dos primeiros versos da canção: "Eu sou assim, quem quiser gostar de mim, eu sou assim", de Wilson Batista.

Teresa Cristina é do samba, de dentro dele. Seu samba é essencialmente o de cadência lenta, de pouca ginga, de poesia elevada, de compositores como Cartola, Nelson Cavaquinho, Ismael Silva, Batatinha, Zé Keti e o próprio Paulinho. Tímida, de gestos pequenos, tem a voz limpa, seca, mais próxima da Bossa Nova que do canto estridente das pastoras. Enuncia cada verso com dicção perfeita, como que recitando, chamando a atenção ao que diz cada canção. Teresa nunca exalta seu canto, quando muito aumenta o volume nos raros partidos-altos do disco, mantendo a interpretação contida, quase fria. Frieza que, em vez de causar desinteresse, nos aproxima de seu canto. Paulinho da Viola, normalmente identificado pelo canto discreto, interpretando ao lado de Teresa Cristina "Depois de tanto amor", parece aproximar-se do bel canto. Nessa estréia e também em discos posteriores, a cantora é acompanhada pelo grupo Semente. Os arranjos do grupo seguem a sua premissa. Delicados, sem virtuosismos, favorecem e abrilhantam seu canto. O grupo registra, ainda, um lado pouco exercido por Paulinho da Viola, o de compositor de choros, presente nesses discos com "Inesquecível" e "Choro negro".

O samba, gênero dado como moribundo desde o nascimento, elege de quando em quando um "salvador". No final dos anos 1960 ,
[1] Entrevista à revistaÉpoca (edição de 15/9/2007). 
[2] Isabel Jaguaribe dedicou um filme ao tema, Paulinho da Viola: meu tempoé hoje, de 2003. foi a vez de Paulinho da Viola. Desde muito jovem alçado à condição de mestre, foi aprisionado pela severa tradição do samba, o que dificultou sua participação na renovação que acontecia na música brasileira, comandada por seus contemporâneos. Ele desejava, ainda que se restringisse apenas ao universo do samba, contribuir para essa renovação. E o fez. Modesto, sem deixar pra trás seu modelo original, Paulinho renovou o gênero, seja na lírica, renovando sua poesia, seja na forma, incorporando, em seus arranjos, harmonias, instrumentos e texturas sonoras estranhas ao samba. Como na linda versão de "O meu pecado" (Zé Keti e Nelson Cavaquinho), presente no disco Foi um rio que passou em minha vida (1970), em que a percussão acústica é retrabalhada em estúdio, adquirindo timbre eletrônico.

Teresa e seus companheiros são os eleitos da vez e a mesma aflição que atingiu Paulinho, que o fez e o faz ainda ter de se defender da dita "condição de passadista" ${ }^{2}$, começa a atingir Teresa Cristina. A cantora, ao lado do grupo Semente, se tornou símbolo da recuperação da Lapa. Levou o samba de volta a um dos seus mais importantes redutos, recuperando o outrora degradado bairro carioca. Teresa, porém, parece assimilar mais essa lição do ídolo e, após se lançar como compositora em Avida mefez assim, de 2004, silenciosamente, ao modo de Paulinho, se desvencilha um pouco da imagem de guardiã do samba. Como prova disso, apresenta uma gravação de "Gema" (Caetano Veloso), presente no seu disco mais recente, Delicada, de 2007. Não deixa de ser curioso que Teresa Cristina identifique no compositor baiano, quarenta anos após a estréia deste, seu passaporte para a contemporaneidade.

Roberta Sá também canta samba, mas não sofre as mesmas cobranças de Teresa Cristina. Não vem do berço do samba, não recebe pressão por continuidade. Apesar de nascida em Natal, no Rio Grande do Norte, Roberta Sá é carioca, sua música é carioca. Essa influência é clara em Sambas e bossas, de 2004 , disco promocional que não chegou ao mercado fonográfico mas já mostrava o universo em que transita a cantora. O disco traz versões de Roberta para clássicos do samba e da Bossa Nova. Destaques são suas versões para "A Flor e o Espinho" (Nelson Cavaquinho e Guilherme de Brito)e "Falsa baiana" (Geraldo Pereira) - esta com arranjo esperto, em que a bateria remete à versão instrumental de "Baixa do sapateiro" (Ary Barroso), gravada por João Gilberto em João Gilberto, de 1973, disco que, aliás, traz a versão definitiva para o samba de Geraldo Pereira.

Braseiro, de 2005, marca a estréia de Roberta Sá. Muito bem recebido, o disco acerta novamente no repertório. Nele, Roberta visita mais uma vez a obra de João Gilberto e regrava "Eu sambo mesmo" (Janet de Almeida). Se, por um lado, mostra de onde vem o samba que canta, por outro revela ousadia ao lidar com o repertório do cantor. Sua voz delicada, precisa, passeia com segurança pelas canções, por vezes sus- 
tentando, por vezes alterando seu ritmo, assimilando lições aprendidas com a Bossa Nova. É desse disco também sua versão de "Pelas tabelas", samba de Chico Buarque, outra grande influência na música de Roberta. Os arranjos desse disco parecem tirados de um disco dele. São claros, modestos até, sem muito espaço para a invenção. Em um disco que privilegia grandes autores ${ }^{3}$, Roberta Sá deixa espaço para jovens compositores. "Casa pré-fabricada", canção de Marcelo Camelo, integrante da banda Los Hermanos, écantada com delicadeza por Roberta. Outro compositor gravado nesse disco éPedro Luís.Com destaque na nova música brasileira, ele assina a canção que dá título ao disco, além de participar com seu grupo A Parede. Roberta canta ainda um samba de Teresa Cristina, "Lavoura", com a participação de Ney Matogrosso. É interessante notar a diferença de sua interpretação em relação à da própria Teresa. Ralentada, a sua versão aumenta a carga de melancolia que a canção traz.

Se não sofre das pressões do mundo do Samba, Roberta parece ter lá as suas próprias. Que belo estranho dia pra se ter alegria, de 2007, parece apontar para isso. Sem abrir mão do samba, amplia seu repertório, trazendo um leve acento pop, muito em razão de privilegiar novos compositores. Pedro Luís aprofunda sua parceria com Roberta e assina quatro faixas do disco: uma delas, "Janeiros", em parceria com a própria cantora, marcando sua estréia como compositora. $O$ compositor ajudou também, nas palavras da cantora, na busca por coisas divertidas e contemporâneas. Essas "coisas" já são notadas na primeira faixa do disco. Em "O pedido" (Junio Barreto e Jam Silva), violões, palmas e percussão de acento flamenco se juntam a uma guitarra quase rock. Outros jovens compositores no disco são Rodrigo Maranhão, Moreno Veloso (que junto com Quito Ribeiro forma uma dupla que tem estado presente nos discos de muitas cantoras, como Jussara Silveira e Gal Costa) e Edu Krieger, que assina "Novo amor", canção de gosto clássico que Roberta canta acompanhada somente pelo grande bandolim de Hamilton de Holanda. Roberta Sá segue seu passo certo, contido, um tanto conservador, buscando se abrir para a nova música brasileira.

Céu quer o novo. E se armou para isso no disco de estréia. Céu, de 2005, traz nos créditos nomes de músicos e artistas que vêm lidando com novas informações na música brasileira, incorporando novos sotaques a ela, apreendidos de estilos musicais como o hip hop, o afrobeat (estilo criado a partir da fusão do jazz com música africana) e o dub (derivação do reggae). Fazem parte dessa cena Nação Zumbi, Instituto, Beto Villares, Curumin, Z'Africa Brazil e Lucas Santana, entre outros.

É com essa turma, ou parte dela, mas certamente sob sua influência, que Céu fez seu disco. O que primeiro chama a atenção é o som desenvolvido nesse trabalho (e não há nisso nenhum demérito, ao contrário,
[3] Canta também no disco "Valsa da solidão", parceria menos conhecida de Paulinho da Viola e Hermínio Bello de Carvalho, e "A vizinha do lado", samba de Dorival Caymmi que alavancou sua carreira. 
já que Céu produziu o disco ao lado de Beto Villares). Essa sonoridade percorre o disco em faixas como "Véu da noite" (Beto Villares e Céu), canção de letra reduzida, com quase sete minutos de duração, em que Céu quase não canta, trazendo para o primeiro plano o belo arranjo de metais, mostrando maturidade ao entender que o disco de uma cantora pode e deve ser mais do que apenas sua voz. Em "Rainha", de sua autoria, Céu deixa transpareceruma influência africana, na letra e ainda mais no arranjo ao estilo de Fela Kuti, músico nigeriano criador do afrobeat. Sobre essa base, sobre esses sons, surge a cantora. É aí que o disco acontece. De timbre original, seu canto um tanto rouco, por vezes sussurrado, nos seduz de início e nos conduz na audição. Esse clima de sedução é ampliado pelos saborosos coros, feitos unicamente por Céu, esbanjando virtuosismo. Na sua versão para "Concrete jungle" (Bob Marley) por exemplo, Céu demonstra enorme intimidade com a canção e emula sozinha o coro característico do reggae. Nesse ponto quero ressaltar o que para mim talvez tenha impedido Céu de alcançar, já na estréia, uma voz ainda mais original. Refiro-me aqui à compositora, que assina a quase totalidade das faixas do disco. Há um descolamento entre a interpretação e o som produzidos no disco em relação às canções propriamente ditas. A intimidade que Céu demonstra com o universo das influências citadas até agora e o modo como se fazem presentes no disco, sempre pela chave da inovação, não encontram correspondente nas composições. Céu confere a estas um papel arcaizante. Na sua maioria, se apóiam em gêneros fundadores da música brasileira, como a ciranda, o samba de roda, a valsa-canção, entre outros. Nas suas letras, abusa de palavras e expressões como "malemolência", "teu nome na boca do sapo", "quebrante", "banzo", "ave cruz", que em nada se relacionam com o lado inventivo do disco, restando a este o papel de modernizador das canções, sem no entanto conseguir transformá-las completamente. É preciso, porém, não confundir seu trabalho com o que há alguns anos foi chamado "drum'n bossa", subgênero musical inventado por artistas que pensavam em recriar os clássicos da Bossa Nova acrescentando a batida do drum'n bass (um dos infinitos estilos dentro da música eletrônica), na ilusão de que fosse possível conferir algo novo à revolução criada por João Gilberto.

Com Céu, o buraco é mais embaixo. A meu ver, seu desafio - e isso vale para os artistas que estão juntos dela - é continuar no trem da história, nesses novos trilhos em que puseram a música brasileira, incorporando-os pelo lado de dentro e não apenas como moldura sonora, para quem sabe assim encontrar novos caminhos. Como ela mesma canta em um verso de sua autoria, "comigo não tem gravata, e se acaso pego o trem errado, vou-me embora".

MPB (música popular brasileira). A sigla, bicho-papão que guardaria em si toda a música feita no Brasil, se tornou nas últimas décadas 
um estilo próprio, à parte do samba e da Bossa Nova por exemplo,e, ao menos aos olhos da nova geração, um rótulo não desejável. Para as jovens cantoras, por exemplo, não cabe mais o posto de diva, da intérprete total, que se transfigura no palco e semeia o público com sua arte. A cena inicial do mais recente filme sobre Maria Bethânia4, para essa geração, é o retrato acabado do cafona. Isso explica a postura indiferente, fria, até blasé, comum a muitos artistas de agora.

Mariana Aydar não teme a MPB. A crise da indústria musical, que em maior ou menor grau interfere na carreira das cantoras a que este artigo se refere, não atingiu seu primeiro disco, Kavita I, de 2006. Lançado por uma grande gravadora, o disco tornou-a um nome rapidamente conhecido e contribuiu para que seu trabalho fosse saudado como uma das grandes novidades da música brasileira.

É ao vivo, mais do que no disco, que ela se revela (característica comum às grandes cantoras da MPB). Não há timidez em Mariana, o palco é dominado. Dona de uma voz poderosa, ela canta para fora, de braços abertos. Seu canto sólido desaba sobre a platéia. É sua profissão de fé. Ela procura entender o significado de cada canção e se emociona com o que canta. Nada mais fora de moda. Freqüentemente é comparada a Clara Nunes, fato também original. Clara Nunes, identificada com os sambas de terreiro e conhecida pela espiritualidade (outro tabu nos dias de hoje que Mariana não teme enfrentar: "Candomblé" é o nome de uma das faixas do disco), não havia encontrado, até então, um par na música brasileira. No disco, Mariana mostra personalidade também ao cantar a canção gravada por Elis Regina, "Menino das laranjas" (Théo de Barros), e assume o risco da comparação com a cantora-mito da música brasileira. "Vento no canavial" (João Donato e Lysias Ênio) traz o balanço reconhecível do pianista. Traz também o clichê, muito usado por velhos arranjadores da MPB, de simular na música o que se diz na letra, criando sons de ventos produzidos por teclados como que a justificar o título da canção.

A música de Mariana Aydar é assim. A intuição é seu grande achado. E se às vezes, contando só com a intuição, esbarra na pieguice, é por causa dela que atinge momentos de grande arte. Diferente de Céu, Mariana não parece ter um projeto de atualização da música brasileira. Tampouco se lança numa jornada saudosista em defesa da tradição. Mariana canta o que lhe parece bom, o que lhe dá prazer. $\mathrm{O}$ perigo para ela é ceder ao ressentimento da tradicional família da música brasileira, que já reivindica sua voz na luta em defesa das cores de nossa gloriosa pátria musical. Na proporção inversa em que falta a Céu encarar a música brasileira, Mariana terá de se livrar dela. A intuição que faz de Mariana uma grande artista deve continuar a movê-la, buscando assim novas maneiras de fazer música, além das que já conhece edomina.
[4] Maria Bethânia revê suas marcas, sinalizadas no chão por adesivos na forma de estrelas e aproveita pra acertar os últimos detalhes do espetáculo que comemora seus sessenta anos de idade e quarenta de carreira. Corta. A cantora agora faz orações, retira os sapatos e se prepara para entrar em seu território sagrado. A câmera a acompanha, desde o camarim até o palco, fechada atrás de sua vasta cabeleira. Então se abre. O que se vê é uma multidão entregue ao carisma de sua voz, que saúda a todos com uma canção de Raul Seixas. Assim começa Pedrinha de Aruanda, 2007, documentário dirigido por Andrucha Waddington. 
[5] Sigla para extended play, nome dado a uma gravação que é longa demais para ser considerada um compacto e muito curta para ser classificada como álbum.

[6] Selo que pertencia à gravadora EMI, criado com a intenção de testar novos artistas, antes de sua contratação em definitivo.
Thalma de Freitas é cantora de samba. Basta conferir o show que vem fazendo acompanhada por Paulão 7 Cordas e que promete virar disco. É crooner de orquestra de baile, sua performance à frente da Orquestra Imperial não deixa dúvidas. É boa compositora. "Não foi em vão" é uma das canções mais bonitas dos últimos anos. Também é atriz de carreira sólida. Para acompanhá-la, é necessário atenção. Sua estréia como cantora foi no disco Thalma, de 1994. Muito fraco, claramente um disco de gravadora, mostra uma artista ainda muito imatura, inspirada pelas cantoras do rhythm'n blues americano. Talvez por isso tenha demorado dez anos para uma nova estréia. Ou quase. Thalma de Freitas, de 2004, é um EP5, lançado pelo selo Cardume ${ }^{6}$. As seis faixas do disco são acompanhadas pelo piano de seu pai, o maestro Laércio de Freitas, pela bateria de Wilson das Neves e pelo ex-baixista do Tamba Trio, Bebeto. O disco é marcado por uma sonoridade de samba-jazz em um repertório que já traz o ecletismo - aparentemente sua marca. Mostrando-se ligada à sua época, cantou "Tranqüilo" (Kassin), uma das primeiras gravações do hoje festejado compositor e produtor. Mostra-se também conhecedora de história, ao cantar, com grande felicidade, o choro "Doce de coco", clássico de Jacob do Bandolim, com letra de Hermínio Bello de Carvalho. Thalma mostra-se versátil e transforma "Cordeiro de nana" (Mateus eDadindo) em uma quase-canção de ninar, diminuindo o volume da voz num canto sussurrado, acompanhada somente pelo delicado piano de Laércio.

Passados alguns anos, Thalma aparece envolvida em mais um projeto, o disco de estréia da Orquestra Imperial, Carnaval só no ano que vem, de 2007. O grupo, formado em 2002 por amigos do Rio de Janeiro, pretendia fixar um ponto de encontro onde pudessem se divertir fazendo música e exercitar outros lados que não existiam no trabalho autoral de cada um. A Orquestra é composta de artistas da nova cena musical carioca, como Kassin, Berna Ceppas, Rodrigo Amarante, Moreno Veloso, Domênico Lancelotti, Pedro Sá e músicos experientes, como Nelson Jacobina e Wilson das Neves. À frente do grupo (ao lado de Nina Becker, outra boa cantora dessa geração), Thalma esbanja segurança nessa espécie de gafieira moderna que é a Orquestra. Ela defende com autoridade boleros, sambas-canção, tangos, valsas, marchas e toda sorte de estilos que normalmente compõem uma orquestra de baile, antiga escola para muitas de nossas grandes cantoras.

Falta ainda a Thalma uma estréia por inteiro, em que mostre os contornos de sua música - ou a falta deles, o que a aproximaria ainda mais de uma cantora com quem já guarda semelhanças, Elza Soares, que ao longo de toda a carreira não facilitou sua classificação. Thalma tem longa jornada à frente e certamente a encherá de desvios e achados. 
Duas características parecem unir o trabalho das cantoras analisadas. A primeira é o fato de todas serem compositoras, acontecimento raro na história da música popular brasileira. A presença do samba é o outro ponto em comum. Embora adquira estaturas diferentes no trabalho de cada uma, o samba as aproxima bastante. E essas características as aproximam também de Marisa Monte, que a meu ver exerce forte influência sobre essa geração, ainda que não declarada. A cantora, que iniciou sua carreira no final dos anos 1980, sempre ligada às gravadoras multinacionais, manteve desde o início uma postura artística independente, fazendo o que quis quando quis e ainda assim conquistando estrondoso sucesso popular. Um sonho para jovens artistas. Marisa faz história também como compositora, tendo criado um novo pop brasileiro, um pouco mais cerebral, muito influenciado pelos tropicalistas. Pelo próprio selo, o Phonomotor, também produz discos, como Tudo azul, de 2000 , da Velha Guarda da Portela. Sua ligação com o samba, aliás, é antiga. Afora o resgate ${ }^{7}$, desde sempre cantou samba e se transformou, ao lado de Teresa Cristina, na principal intérprete contemporânea de Paulinho da Viola. Sua gravação de "Dança da solidão" no disco Verde anil amarelo cor-de-rosa e carvão, de 1994, está aí como prova. Cantando sambas dele, deu a Paulinho um lugar que nenhuma cantora havia dado e acabou por se tornar parceira em um deles. Ainda que Marisa cante samba desde o início e tenha mesmo feito os seus próprios, o gênero aparece como um capítulo à parte em seu trabalho, com grande relevância, é verdade, mas ainda separado do todo, chegando mesmo a ser reunido em um disco dedicado inteiramente a ele ${ }^{8}$. Talvez a diferença dessa nova geração em relação a Marisa Monte seja justamente o modo como encaram o samba. Para nossas novas cantoras, o samba, em maior ou menor grau, atua como um identificador da nossa música. Elas tentam tomá-lo como norte na busca de uma nova música brasileira.

Em texto para "O Pasquim"9, ao se referir ao disco Gal, de 1969, Caetano Veloso escreve que "não é fácil a pessoa chegar inteira ao final de um disco" e que Gal devia ter brigado muito para fazê-lo. Se nossas jovens cantoras não se mostraram por inteiras, ao menos já demonstraram disposição para a briga.

ROMUlo FróEs, cantor e compositor paulistano, tem dois discos lançados:Calado (2004) e Cão (2006).
[7] Além do disco da Velha Guarda da Portela, lançou também dois velhos sambistas que nunca ou pouco haviam gravado, Argemiro do Patrocínio e Seu Jair do Cavaquinho.

[8] Universo ao meu redor, de 2006 seu disco só de sambas, foi lançado simultaneamente a Infinito particular, de 2006, que traz o que não é samba em sua música.

[9] "O Pasquim", 19/2/1970.

\begin{tabular}{l}
\hline Recebido para publicação \\
em 14 de novembro de 2007. \\
\hline NOVOS ESTUDOS \\
CEBRAP \\
79 , novembro 2007 \\
pp. $229-236$ \\
\hline
\end{tabular}

